\title{
Airway hyperresponsiveness in asthma: mechanisms, clinical significance, and treatment
}

\author{
John D. Brannan ${ }^{1}$ and M. Diane Lougheed ${ }^{2,3}$ \\ 1 Respiratory Function Laboratory, Department of Respiratory and Sleep Medicine, Westmead Hospital, Sydney, NSW, Australia \\ 2 Department of Medicine (Respirology), Queen's University, Kingston, ON, Canada \\ ${ }^{3}$ Department of Biomedical and Molecular Sciences (Physiology), Queen's University, Kingston, ON, Canada
}

\section{Edited by:}

John T. Fisher, Queens University,

Canada

\section{Reviewed by:}

Stuart Mazzone, University of

Queensland, Australia

François Marchal, CHU de Nancy,

France

${ }^{*}$ Correspondence:

John D. Brannan, Respiratory

Function Laboratory, Department of

Respiratory and Sleep Medicine,

Westmead Hospital, Corner of

Hawkesbury and Darcy Roads,

Westmead, Sydney, NSW 2145,

Australia.

e-mail: john.brannan@sydney.edu.au
Airway hyperresponsiveness (AHR) and airway inflammation are key pathophysiological features of asthma. Bronchial provocation tests (BPTs) are objective tests for AHR that are clinically useful to aid in the diagnosis of asthma in both adults and children. BPTs can be either "direct" or "indirect," referring to the mechanism by which a stimulus mediates bronchoconstriction. Direct BPTs refer to the administration of pharmacological agonist (e.g., methacholine or histamine) that act on specific receptors on the airway smooth muscle. Airway inflammation and/or airway remodeling may be key determinants of the response to direct stimuli. Indirect BPTs are those in which the stimulus causes the release of mediators of bronchoconstriction from inflammatory cells (e.g., exercise, allergen, mannitol). Airway sensitivity to indirect stimuli is dependent upon the presence of inflammation (e.g., mast cells, eosinophils), which responds to treatment with inhaled corticosteroids (ICS). Thus, there is a stronger relationship between indices of steroid-sensitive inflammation (e.g., sputum eosinophils, fraction of exhaled nitric oxide) and airway sensitivity to indirect compared to direct stimuli. Regular treatment with ICS does not result in the complete inhibition of responsiveness to direct stimuli. AHR to indirect stimuli identifies individuals that are highly likely to have a clinical improvement with ICS therapy in association with an inhibition of airway sensitivity following weeks to months of treatment with ICS. To comprehend the clinical utility of direct or indirect stimuli in either diagnosis of asthma or monitoring of therapeutic intervention requires an understanding of the underlying pathophysiology of AHR and mechanisms of action of both stimuli.

Keywords: airway hyperresponsiveness, bronchial provocation, asthma, pharmacotherapy, diagnosis

\section{INTRODUCTION}

Airway hyperresponsiveness (AHR) is one of the hallmark features of asthma. Bronchial provocation tests (BPTs) are used to assess the presence of AHR to assist in making a clinical diagnosis of asthma in individuals with symptoms and signs that suggest asthma. Asthma is defined as a chronic inflammatory disorder of the airways in which many cells and cellular elements play a role [Global Initiative for Asthma (GINA), 2007]. The chronic inflammation is associated with AHR that leads to recurrent episodes of wheezing, chest tightness, and coughing [Global Initiative for Asthma (GINA), 2007]. It is also understood that the pathophysiology of asthma can lead to a variety of more permanent changes in the airway, which is commonly known as "remodeling" (Holgate et al., 2010). Asthma symptoms are the most clinically accessible marker of disease activity. However, symptoms often do not reflect the degree of airway inflammation and AHR, the two key features attenuated by the mainstay therapy for asthma, inhaled corticosteroids (ICS; Sont et al., 1996).

Bronchial provocation tests are useful in a clinical setting if spirometry is normal and a reversibility test using a standard dose of $\beta_{2}$-agonist does not demonstrate significant reversibility or bronchodilatation. They may also be useful if a past history of asthma has not been substantiated by objective measures of lung function documenting reversible airflow obstruction, as well as in the evaluation of atypical symptoms such as chronic cough (Irwin, 2006). BPTs may be particularly relevant to perform prior to beginning an occupation or sporting activity that may exacerbate or cause an attack of asthma, and to diagnose and monitor work-related asthma (Tarlo et al., 2008).

Bronchial provocation tests have played a significant role in research to understand mechanisms of AHR, mechanisms of dyspnea and cough in asthma (Lougheed et al., 1993, 1995; Turcotte and Lougheed, 2011) and to investigate the efficacy of pharmacotherapy used in the prevention of AHR and treatment of asthma (O’Byrne et al., 2009a). BPTs have been used to investigate AHR following both short- and long-term treatment with regular ICS in order to justify changes in ICS dose in a clinical setting (Sont et al., 1999; Lipworth et al., 2012; Turton et al., 2012).

This review will discuss the BPTs available for clinical use and outline the different mechanisms by which each test identifies AHR. We will review the effects of pharmacotherapy used in the treatment of asthma that inhibits AHR, for the purposes of documenting efficacy of treatment in research or in an individual in the clinic. Where possible we will demonstrate the differences and 
similarities between adults and children however the majority of research cited pertains to adult asthma.

\section{DIRECT BRONCHIAL PROVOCATION TESTS}

Direct BPTs refer to the use of single agonist such as methacholine or histamine that act directly on receptors on the airway smooth muscle (ASM) causing contraction. The most widely used is methacholine which acts on muscarinic $\left(\mathrm{M}_{3}\right)$ receptors, while histamine acts on $\mathrm{H}_{1}$ receptors (Figure 1). These agents are administered using standardized protocols either through tidal breathing using a nebulizer or deep inhalations using a dosimeter method (Ryan et al., 1981; Crapo et al., 2000), while documenting the response to each dose. A $20 \%$ fall in the forced expiratory volume in $1 \mathrm{~s}\left(\mathrm{FEV}_{1}\right)$ is considered as a positive test and the provocative concentration $\left(\mathrm{PC}_{20}\right)$ or dose $\left(\mathrm{PD}_{20}\right)$ of agonist to cause this fall is calculated by interpolation from the dose-response curve. Methacholine has regulatory approval by the United States Food and Drug Administration (US FDA) and Health Canada, however no such approvals have been obtained for histamine.

Individuals with asthma often are more sensitive and reactive to these agents compared with those who do not have asthma. It is now better understood that AHR to direct stimuli can be considered to have two components of the response that are considered "fixed" and "variable" (Cockcroft, 2010). The variable component is considered to change rapidly, for example following inhalation of an allergen which can increase AHR by acutely upregulating airway inflammation. Alternatively, regular use of ICS, which are potent anti-inflammatory agents, is known to attenuate, though not completely inhibit AHR to direct agents (Brannan, 2010). Thus, the variable component is considered to reflect the inflammatory aspect of AHR to direct agents. Conversely, the fixed component is thought to reflect more chronic persistent (possibly permanent) structural and functional changes in the airway that may or may not be due to airway inflammation, such as airway remodeling (Cockcroft, 2010). AHR can persist despite high-dose ICS over long treatment periods (Sont et al., 1996; Brannan, 2010). The different contribution each component has on the airway sensitivity to direct stimuli cannot be determined from a single test as little research has been performed in an attempt to elucidate the components of the response. For example, it is possible that some individuals who do not have asthma may respond to direct agents (Hewitt, 2008) in the absence of an inflammatory component at the time of testing, potentially indicating the presence of a remodeling process.

Direct tests are considered to have a high diagnostic sensitivity for the presence of current asthma (Cockcroft, 2010). That is, most individuals with a clinical diagnosis of asthma will respond to these stimuli. However, several recent studies suggest that in some patient groups the diagnostic sensitivity of direct stimuli may not be as high as initially reported. The diagnostic sensitivity of

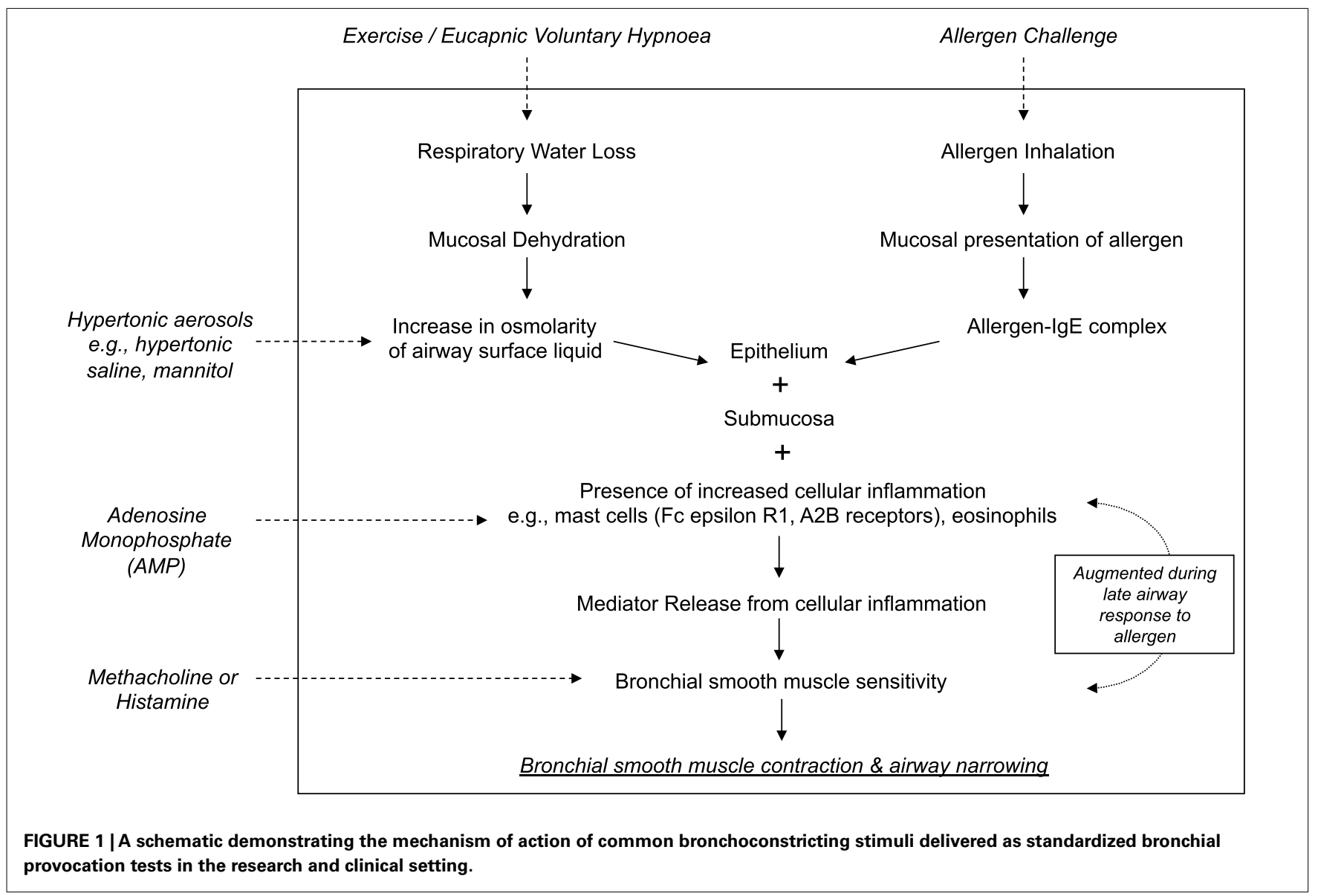


methacholine in asthmatics taking regular ICS has been reported to be $77 \%$, while the sensitivity was significantly reduced in Caucasians (69\%) compared to African Americans (95\%; Sumino et al., 2012). Further, there was a significant reduction in sensitivity when comparing those who were non-atopic (52\%) versus atopic $(82 \%)$. A similar decrease in diagnostic sensitivity of methacholine to identify asthma has been observed in non-atopic versus atopic children in cohort studies (Liem et al., 2008). Further, there is increasing evidence that AHR to direct stimuli has a low sensitivity to identify the presence of exercise-induced bronchoconstriction (EIB) in adults and children (Haby et al., 1994; Holzer et al., 2002; Anderson et al., 2009; Sue-Chu et al., 2010; Holley et al., 2012). That is, individuals with significant EIB may have no airway sensitivity to direct stimuli. However protocols that require the administration of methacholine using a deep inspiration have demonstrated decreased sensitivity to identify AHR compared to those using a tidal breathing method (Todd et al., 2004; Cockcroft and Nair, 2012). It is well established that a deep inhalation can have a protective effect on AHR in non-asthmatics (Kapsali et al., 2000). It has been hypothesized that the attenuation of the bronchodilator and/or bronchoprotective effect of a deep inspiration contribute to the severity of the clinical manifestations of asthma (Scichilone et al., 2007). However evidence for this bronchoprotection has been observed in mild asthmatics and it may be lost in the presence of more active airway inflammation and poorer lung function (Allen et al., 2008; Pyrgos et al., 2011).

Epidemiologic studies in adults and children have established that direct BPTs can have a low specificity for asthma (Woolcock and Peat, 1989). For example, it is well established that individuals with other lung disease, atopy, allergic rhinitis, and individuals who smoke may demonstrate AHR to direct stimuli (Ramsdale et al., 1985; Tashkin et al., 1992; Britton et al., 1994; Sunyer et al., 1997; Hewitt, 2008). It is not clear why these subjects respond however, it is possible that either one of or both the variable and fixed components may be present. There is evidence that reduced airway caliber may be a predictor of the response (Britton et al., 1994; Litonjua et al., 1999; Parker and McCool, 2002; Parker et al., 2003). Further, larger airways may provide some protective effect on the airway response in individuals with asthma. In a large population of physician-diagnosed asthmatics, it was observed that $27 \%$ had a negative methacholine challenge test and these subjects were more likely to have better lung function than those who had a positive test (McGrath and Fahy, 2011). Other evidence to support airway size being a determinant of AHR to direct stimuli arises from studies demonstrating that the severity of AHR decreased with age from childhood to adolescence (Sears et al., 2003). Imaging studies in humans have not provided clear evidence between a relationship with airway sensitivity to methacholine and lung function (Boulet et al., 1989).

There can be a high prevalence of AHR to direct stimuli in athletes, in particularly winter athletes who do not demonstrate significant EIB (Sue-Chu et al., 2010). This observation has supported the concept that AHR to these agents in these subjects may identify a type of airway damage or remodeling due to the effects of high intensity exercise (Kippelen et al., 2012).

In well established asthmatic populations, there is evidence of a relationship between the airway sensitivity to direct stimuli and clinically accessible markers of inflammation such as sputum eosinophils, as well as non-specific markers of inflammation such as the fraction of exhaled nitric oxide (FeNO; Jatakanon et al., 1998). However, others have not shown such relationships in patients with well established allergic asthma (Crimi et al., 1998). These differences may be accounted for by the presence of remodeling and its influence on the airway sensitivity to these agents.

\section{INDIRECT BRONCHIAL PROVOCATION TESTS}

Indirect BPTs refer to stimuli such as dry air hyperpnea or stimuli administered via an aerosol such as allergens, osmotic agents (e.g., mannitol or hypertonic saline), or adenosine monophosphate (AMP), that cause the release of a variety of mediators of bronchoconstriction from inflammatory cells (Figure 1). Mediators such as histamine, prostaglandins, and leukotrienes then act on specific receptors on the ASM to cause contraction and airway narrowing. The mast cell is thought to play a dominant role in contributing to the source of mediators (Anderson, 2010). Tryptase containing mast cells predominate in lung tissue (Andersson et al., 2009), however it is their location in the airway epithelium and the ASM that may be of significant importance in AHR (Brightling et al., 2002; Dougherty et al., 2010). There may be some involvement from airway sensory nerves, in particular to dry air hyperpnea and the osmotic stimuli as a result of airway cooling and changes in osmolarity (Anderson et al., 1996).

Inhaled allergens cause mast cell degranulation by crosslinking with Immunoglobulin E via the FceRI receptor on the surface of the mast cell. Both dry air hyperpnea and osmotic stimuli are considered to raise the osmolarity of the airway surface, leading to movement of water into the airway lumen and a resultant increase in airway tissue osmolarity. It has been demonstrated in vitro that the mast cell is sensitive to osmotic change, with the ability to release histamine, prostaglandins, and leukotrienes, importantly in the presence of IgE (Eggleston et al., 1984, 1990; Gulliksson et al., 2006). AMP acts directly on mast cells to cause degranulation and release of mediators via action on the $\mathrm{A} 2 \mathrm{~b}$ receptor (Van Schoor et al., 2000).

Indirect test protocols include exercise testing either via a treadmill or cycle ergometer, eucapnic voluntary hyperventilation (EVH), nebulized hypertonic saline, inhaled dry powder mannitol, or AMP, all of which have well established and standardized protocols (Van Schoor et al., 2000; Anderson and Brannan, 2003). Inhaled mannitol has been approved by regulatory authorities in 26 countries including the US FDA as a standardized test kit (www.mannitoltest.info). Allergen inhalation is primarily used in research as it can cause a late airway response approximately $6-8 \mathrm{~h}$ following the early bronchoconstriction (O'Byrne et al., 2009a). However, the clinical use of specific allergen inhalation tests is limited to specialized tertiary care centers, for example to evaluate work-related asthma (Tarlo et al., 2008).

Exercise and EVH are given as a bolus dose of ventilation and changes in airway caliber are measured by the forced expiratory volume in $1 \mathrm{~s}\left(\mathrm{FEV}_{1}\right)$ over 15-20 min following the stimulus and comparing this to the baseline $\mathrm{FEV}_{1}$ value (Anderson and Brannan, 2003). A positive response is documented as a $10-15 \%$ fall in $\mathrm{FEV}_{1}$ and the severity of the response is determined by the degree 
of the fall in $\mathrm{FEV}_{1}$. In known asthmatics, large falls in $\mathrm{FEV}_{1}$ can be observed when using these tests so for clinical use they are often confined to individuals who are suspected of having EIB with normal lung function (Brannan et al., 1998; Porsbjerg and Brannan, 2010). These tests differ from the dose-response challenges such as the osmotic stimuli or AMP where, like the direct challenges, the stimulus is given in increasing doses and changes in $\mathrm{FEV}_{1}$ are documented until a $15 \%$ (mannitol, hypertonic saline) or $20 \%$ (AMP) fall or no target response is obtained by the maximum dose. The airway sensitivity is defined as the provoking dose of the stimulus to cause a 15 or $20 \%$ fall in $\mathrm{FEV}_{1}$ which is calculated by linear interpolation of the dose-response curve $\left(\mathrm{PD}_{15}\right.$ or $\left.\mathrm{PD}_{20}\right)$. Some studies have investigated the use of a $10 \%$ fall in $\mathrm{FEV}_{1}$ to mannitol $\left(\mathrm{PD}_{10}\right)$ for both monitoring ICS and identifying EIB in elite athletes (Holzer et al., 2003; Lipworth et al., 2012). These tests have a good safety profile as large falls in $\mathrm{FEV}_{1}$ can be avoided (Joos et al., 2003; Brannan et al., 2005).

There have been few studies firmly establishing the use of these challenge tests to investigate conditions that may mimic asthma or EIB, such as laryngeal obstruction (e.g., vocal chord dysfunction), inspiratory stridor, or other conditions such as hyperventilation syndrome in either adults or children (McFadden and Zawadski, 1996; Rundell and Spiering, 2003; Weinberger and AbuHasan, 2007). The presence of symptoms suggestive of asthma, in the absence of AHR to an indirect test certainly warrants further investigation. Additional investigations which may be helpful include examination of the shape of the flow-volume loop, direct laryngoscopy, and the measurement of end-tidal $\mathrm{CO}_{2}$ on exercise.

The mechanism by which indirect stimuli identify AHR is similar to most clinically relevant stimuli that cause AHR in individuals with asthma. These stimuli require the presence of inflammation in the airway. Thus, a response to these stimuli identifies the interaction of the two key features of asthma, inflammation, and AHR. It has been well established that the airway sensitivity to indirect agents is related to the presence and degree of airway inflammation. The severity of the airway response to hypertonic saline is related to the presence of mast cells in brush biopsy and in sputum in children (Gibson et al., 1998, 2000). Those with EIB demonstrate significantly greater numbers of mast cells in the airway epithelium compared to those without EIB (Hallstrand et al., 2011). There are significantly more eosinophils in the sputum of asthmatics with EIB compared to those without EIB and there is a relationship with the presence of eosinophils in sputum and the severity of EIB (Yoshikawa et al., 1998; Kivity et al., 2000; Duong et al., 2008) and the airway sensitivity to mannitol (Porsbjerg et al., 2008). Further, studies comparing direct and indirect BPTs have demonstrated that the airway sensitivity to both AMP and mannitol have a significant relationship to the degree of eosinophils in induced sputum when compared to methacholine in the same asthmatic subjects (Van Den Berge et al., 2001; Porsbjerg et al., 2008; Figure 2). There are also studies identifying significant relationships with FeNO, a non-specific marker of airway inflammation with the airway sensitivity to exercise and mannitol (Scollo et al., 2000; Porsbjerg et al., 2008; Figure 3). However, a proportion of asthmatics who have airway sensitivity to mannitol have FeNO values well within the normal range (i.e., $<20 \mathrm{ppb}$; Porsbjerg et al., 2008; Cowan et al., 2010). Further, both eosinophilic and non-eosinophilic phenotypes have been observed in asthmatics responsive to both hypertonic saline and mannitol (Simpson et al., 2006; Porsbjerg et al., 2009). Non-eosinophilic phenotypes
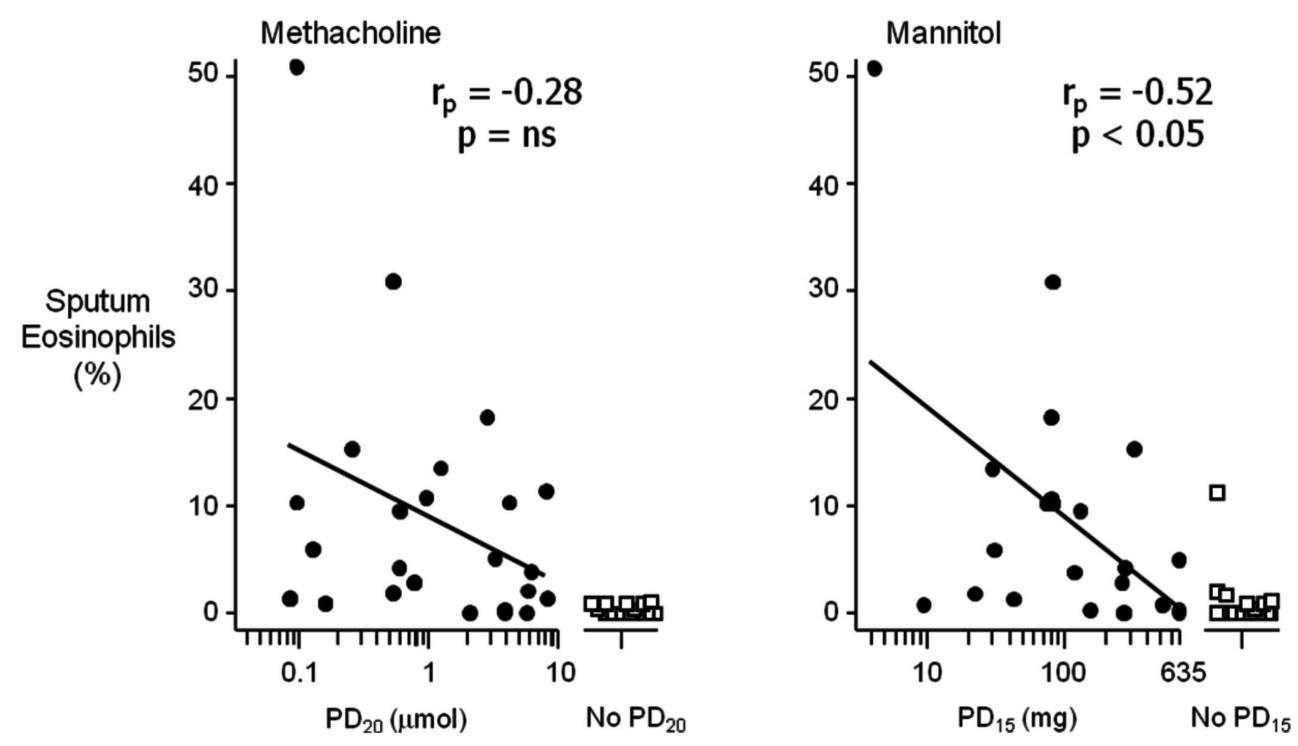

FIGURE 2 |The relationship between the airway sensitivity to inhaled methacholine and mannitol compared to the percentage (\%) of eosinophils in sputum in a selected group of steroid naïve asthmatic subjects. Airway hyperresponsiveness (AHR) to mannitol is defined as a $15 \%$ reduction in the forced expiratory volume in $1 \mathrm{~s}\left(\mathrm{FEV}_{1}\right)$ to a cumulative dose of less than $635 \mathrm{mg}\left(\mathrm{PD}_{15}\right)$; for methacholine as a $20 \%$ reduction in $\mathrm{FEV}_{1}$ to less than eight micromoles $\left(\mathrm{PD}_{20}\right)$. The relationship of \% eosinophils with those who had a positive AHR (closed circles) was significant for mannitol $\left(r_{p}=-0.52, p<0.05\right)$ compared to methacholine $\left(r_{p}=-0.28, p=n s\right)$. Those who had no AHR to either mannitol or methacholine (open squares) in this group of subjects had significantly less sputum eosinophils (adapted from Porsbjerg et al., 2008) 

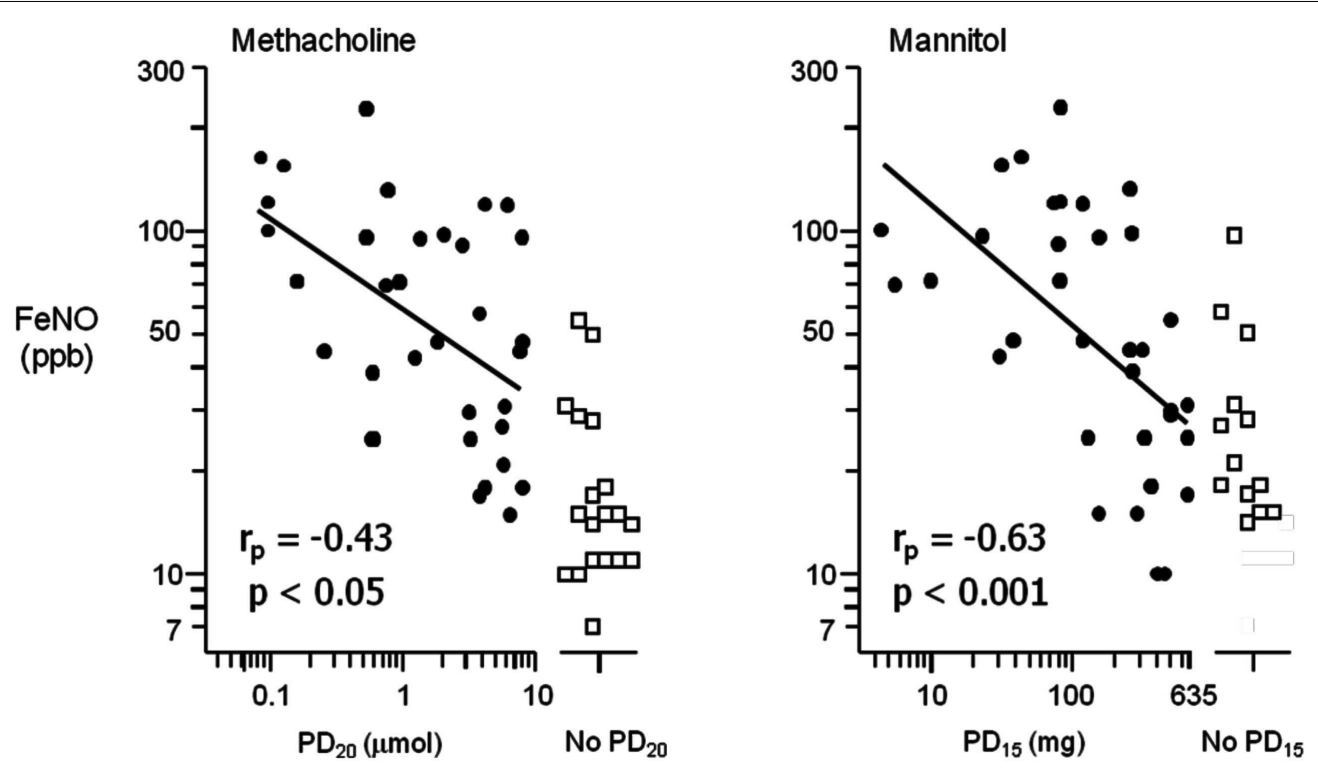

FIGURE 3 |The relationship between the airway sensitivity to inhaled methacholine and mannitol compared to the fraction of exhaled nitric oxide (FeNO) in parts per billion (ppb) in a selected group of steroid naïve asthmatic subjects. Airway

hyperresponsiveness (AHR) to mannitol is defined as a $15 \%$ reduction in the forced expiratory volume in $1 \mathrm{~s}\left(\mathrm{FEV}_{1}\right)$ to a cumulative dose of less than $635 \mathrm{mg}\left(\mathrm{PD}_{15}\right)$; for methacholine as a $20 \%$ reduction in $F E V_{1}$ to less than eight micromoles $\left(\mathrm{PD}_{20}\right)$. The relationship of FeNO with those who had a positive AHR (closed circles) was more significant for mannitol $\left(r_{p}=-0.63, p<0.001\right)$ compared to methacholine $\left(r_{p}=-0.43, p<0.05\right)$ There were a proportion of subjects with AHR that had normal FeNO values (adapted from Porsbjerg et al., 2008). may include those with neutrophils or those who have neither neutrophils or eosinophils in sputum (also known as paucigranulocytic). These studies have shown milder AHR to indirect stimuli in subjects with a non-eosinophilic phenotype. This data suggests that there are subjects with AHR which involves active mast cells in the absence of significant eosinophilia or raised FeNO levels.

There is increasing evidence that indirect stimuli cause mast cell mediator release in vivo. Studies attempting to measure mediators of bronchoconstriction have identified increases in arterial plasma histamine levels measured at the time of maximal airway narrowing to exercise (Anderson et al., 1981). Leukotriene $\mathrm{E}_{4}\left(\mathrm{LTE}_{4}\right)$ or the metabolite of prostaglandin $\mathrm{D}_{2}, 9 \alpha, 11 \beta-\mathrm{PGF}_{2}$, a marker of mast cell release, are measured in urine (Reiss et al., 1997; O'Sullivan et al., 1998b; Mickleborough et al., 2003) and sputum (Hallstrand et al., 2005) following EIB. Similar observations identifying increases in urinary $9 \alpha, 11 \beta-\mathrm{PGF}_{2}$ have been made with mannitol, hypertonic saline (in children), and EVH (Brannan et al., 2003; Mai et al., 2005; Kippelen et al., 2010) as well as allergen challenge (O'Sullivan et al., 1998a), further supporting the role of the mast cell in the airway response to these stimuli. Some of these studies have also found an increase in both $9 \alpha, 11 \beta-\mathrm{PGF}_{2}$ and $\mathrm{LTE}_{4}$ in the urine of non-asthmatics who have no BHR with indirect stimuli (Brannan et al., 2003; Mickleborough et al., 2003; Mai et al., 2005). Thus, the sensitivity of the ASM is an important component of the response to indirect stimuli.

The degree of AHR to direct stimuli is often associated with the airway sensitivity to indirect stimuli in individuals with established asthma (Anderson et al., 1997; Koh and Choi, 2002). However, airway responses to indirect stimuli can occur in the absence of AHR to either methacholine or histamine in adults and children (Haby et al., 1994; Holzer et al., 2003; Anderson et al., 2009; Holley et al., 2012). The explanation for the lack of relationship presumably lies in the differences in mechanisms of action of both direct and indirect stimuli. A variety of endogenous mediators are involved in the airway response to indirect stimuli. These include leukotrienes and prostaglandins which are both known to be more potent at causing airway narrowing than methacholine or histamine (O'Hickey et al., 1988). Thus EIB in the absence of an airway response to direct stimuli may be a result of a heightened sensitivity to endogenous mediators (Anderson, 2010).

\section{ASSESSING EFFICACY OF ASTHMA PHARMACOTHERAPY USING AHR \\ DIRECT AHR}

Airway hyperresponsiveness to direct stimuli is used as a research tool in drug development to assess the efficacy of new and existing therapies used in the acute and long-term treatment of asthma. The ability of these therapies to inhibit AHR has in turn provided some explanation as to the mechanisms of direct AHR. Acutely, $\beta_{2}$-agonists are powerful inhibitors of ASM contractility capable of decreasing AHR to direct stimuli (Page and Spina, 2006). $\beta_{2}$-agonists protect against ASM contraction from direct stimuli by non-specific functional antagonism via $\beta_{2}$ receptorinduced ASM relaxation. The methacholine challenge is a recognized methodology for assessing efficacy and duration of action of bronchoprotection and the pharmacoequivalence of $\beta_{2}$-agonists (Parameswaran et al., 1999; O'Byrne et al., 2009b). While these drugs are the most effective pharmacotherapy to inhibit the airway response to direct stimuli, the protection is not complete in all subjects (Page and Spina, 2006). Asthmatics who regularly use 
$\beta_{2}$-agonists can demonstrate increased airway sensitivity to direct stimuli, a decreased bronchoprotection, as well as a slower recovery to these challenge tests following a standard dose of rescue $\beta_{2}$-agonist (Cheung et al., 1992; Kalra et al., 1996; Haney and Hancox, 2005). This may need to be considered when investigating the efficacy of a $\beta_{2}$-agonist.

The acute use of a leukotriene antagonist and the mast cell stabilizing drugs demonstrate minimal to no effect on AHR to direct stimuli (Patel, 1984; Boner et al., 1987; Crimi et al., 1987; Davis and Cockcroft, 2005). This suggests there are limitations in using direct stimuli to investigate the bronchoprotective effect of antagonists that target other receptors or agents that stabilize the mast cell. However, long-term use of cromoglycate and montelukast has shown some small effect on attenuating the sensitivity to direct stimuli (Bel et al., 1990; Groot et al., 1992; Hakim et al., 2007). The short acting anti-cholinergic ipratropium bromide has a potent inhibitory effect on AHR to methacholine that is lost over $12 \mathrm{~h}$ (Crimi et al., 1992; Illamperuma et al., 2009). However the longer acting anti-cholinergic tiotropium demonstrates more potent inhibition and longer duration of protection against methacholine-induced bronchoconstriction (O'Connor et al., 1996).

Regular use of ICS can attenuate direct AHR (Juniper et al., 1990; Reddel et al., 2000). AHR to direct BPTs have been used to guide the dose of ICS to monitor asthma compared to asthma guidelines in both adults and children (Sont et al., 1999; Nuijsink et al., 2007). However, AHR to direct stimuli may remain in many individuals with asthma on long-term ICS therapy over months to years of treatment (Figure 4). The short-term improvements in direct AHR as a result of ICS therapy may be related to reductions in airway inflammation (du Toit et al., 1997), while more longterm improvement in AHR may be indicative of a reduction in airway remodeling (Sont et al., 1999).
The repeated evaluation of direct AHR to aid in clinical monitoring of the efficacy of ICS was made using a treatment strategy aimed at reducing AHR to methacholine (AHR strategy) compared to a parallel group who were treated based on recommendations in the existing guidelines (reference strategy) in asthmatic adults (Sont et al., 1999). Following 2 years of ICS therapy, there was a 1.8-fold lower incidence of mild exacerbations and a significantly sustained improvement in pre-bronchodilator $\mathrm{FEV}_{1}$ using the AHR strategy. This was associated with improvements in the reticular layer thickness beneath the epithelium, suggesting improvements in airway remodeling. Interestingly, AHR documented as a mean $\mathrm{PC}_{20}$ to methacholine of $0.47 \mathrm{mg} / \mathrm{mL}$ before treatment, was not attenuated using the AHR strategy (increase in $\mathrm{PC}_{20} 1.1$ doubling concentrations, not statistically significant). This confirmed previous studies showing that long-term treatment with ICS does not necessarily reduce AHR to methacholine to anywhere near the normal range (e.g., $>16 \mathrm{mg} / \mathrm{mL}$ ) or abolish AHR to direct stimuli (Figure 4; du Toit et al., 1997; Lim et al., 1999). A similar study in asthmatic children over 2 years found no increase in the number of symptom-free days using the AHR strategy (Nuijsink et al., 2007). They did however observe a better pre-bronchodilator $\mathrm{FEV}_{1}$ in a sub-group of allergic asthmatic children. To afford these clinical benefits, both studies observed the use of higher dose of ICS using the AHR strategy. While these results are inconclusive about monitoring ICS with direct stimuli these studies demonstrate it is difficult to identify optimal therapy when the AHR to these stimuli remains.

\section{INDIRECT AHR}

Pharmacotherapy for the treatment of asthma has also revealed much about the mechanism of indirect AHR. Acute use of $\beta_{2}$-agonists demonstrates the most potent protective effect on indirect stimuli, likely due to a combination of non-specific

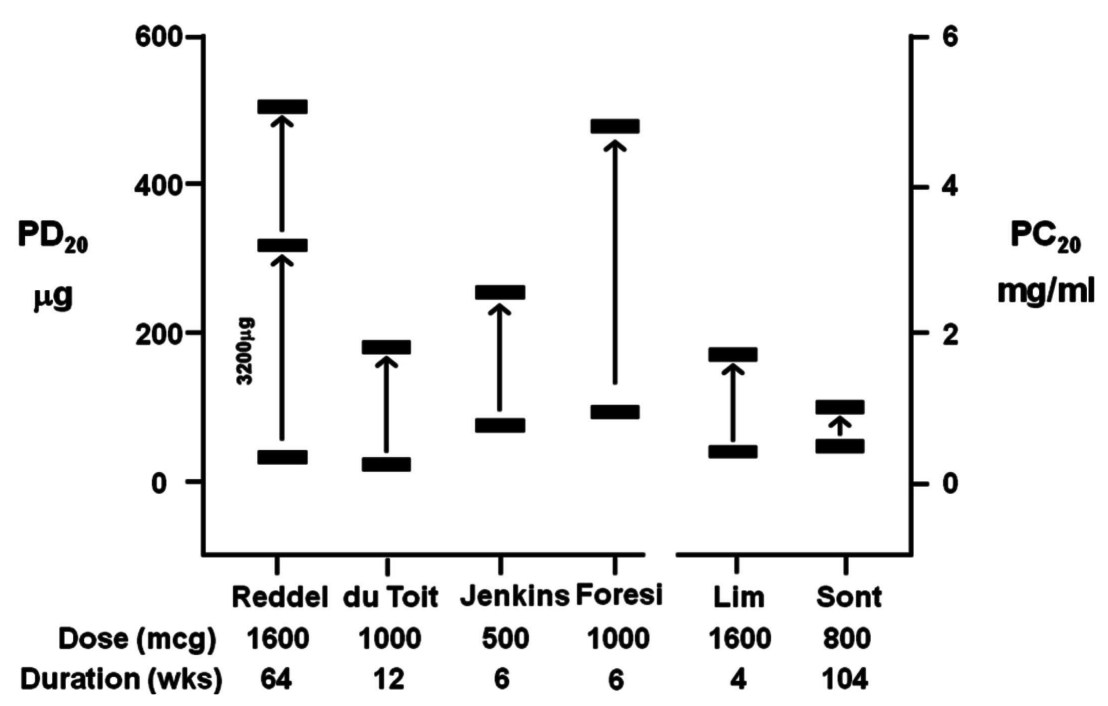

FIGURE 4 | A summary of the improvement in AHR following treatment with inhaled corticosteroids (ICS) expressed as a provoking dose (PD20) or provoking concentration (PC20) to cause a $20 \%$ fall in FEV1 from six studies using either histamine or methacholine (du Toit et al., 1997; Lim et al., 1999; Sont et al., 1999; Reddel et al., 2000; Foresi et al., 2005; Jenkins et al., 2005). Significant AHR to direct stimuli remains in the presence of high doses of ICS over short- and long-term treatment periods. 
functional antagonism of the released mediators causing bronchoconstriction, as well as via $\beta_{2}$-receptor-mediated mast cell stabilization (Anderson et al., 2006). However, regular use of $\beta_{2}$ agonists, like their effects on direct stimuli, may increase the airway sensitivity to indirect stimuli, decrease the ability of $\beta_{2}$-agonists when used acutely to bronchoprotect, and have decreased efficacy when being used to recover from indirect bronchoconstriction (Hancox et al., 2002; Anderson et al., 2006; Haney and Hancox, 2006). Acute use of drugs such as sodium cromoglycate and nedocromil sodium inhibits AHR to indirect stimuli due to their mast cell stabilizing properties (Brannan et al., 2000, 2006; Kelly et al., 2001; Kippelen et al., 2010). The expected increases in the urinary excretion of the mast cell marker $9 \alpha, 11 \beta-\mathrm{PGF}_{2}$ following both mannitol and $\mathrm{EVH}$ are attenuated in the presence of cromoglycate and a $\beta_{2}$-agonist (Brannan et al., 2006; Kippelen et al., 2010). The mast cell stabilizing drugs may also play a role by inhibiting airway sensory nerves or acting on the airway epithelium (Anderson et al., 1996), however they have little effect on suppressing cough to osmotic stimuli in relation to their powerful inhibitory effect on indirect AHR (Koskela et al., 2005). Leukotriene antagonists such as montelukast are powerful at inhibiting the action of leukotrienes on the ASM, causing a rapid recovery from AHR to indirect stimuli (Reiss et al., 1997; Brannan et al., 2001). Histamine antagonists have a weak though noticeable effect on reducing airway sensitivity to some indirect stimuli (Brannan et al., 2001; Anderson and Brannan, 2002; Dahlen et al., 2002). Research using these drugs has revealed the importance of the mast cell and pre-formed histamine on the initial airway response, while leukotrienes are subsequently released "de novo" to sustain bronchoconstriction to indirect stimuli. Anti-cholinergic drugs do demonstrate inhibition on indirect stimuli such as exercise and hypertonic saline (Boulet et al., 1989). However the protection is incomplete and not uniform, demonstrating wide interindividual variability. However this does not diminish the role of the neural response to indirect stimuli, as it is well known that these stimuli can activate sensory nerves which are likely responsible for cough, even in the absence of bronchoconstriction (Koskela et al., 2004, 2005). There is some evidence that interindividual variability for the bronchoprotection to exercise is related to the degree of cardiac vagal activity (Knopfli et al., 2005). However there is little data assessing the role of the newer more potent anti-cholinergics on BHR to indirect stimuli and further research is warranted to investigate the role of airway sensory nerves.

The regular use of ICS is well known to attenuate but also abolish the airway sensitivity to indirect stimuli (Koh et al., 2007). Abolishing responses to indirect stimuli using ICS may provide an objective marker for asthma control (Brannan, 2010). Such an endpoint may also indicate an opportunity for down-titration of ICS dose (Leuppi et al., 2001; Brannan et al., 2012). It is well established that both mast cells and eosinophils, known to be sensitive to ICS, play an important role in the airway response. Both cells are known to decrease in number in the presence of regular ICS therapy (Djukanovic et al., 1992). Thus, an airway response to an indirect stimuli is thought to identify an individual who is likely to have AHR that will benefit from ICS. Thus they have potential for monitoring the efficacy of ICS in both adults and children
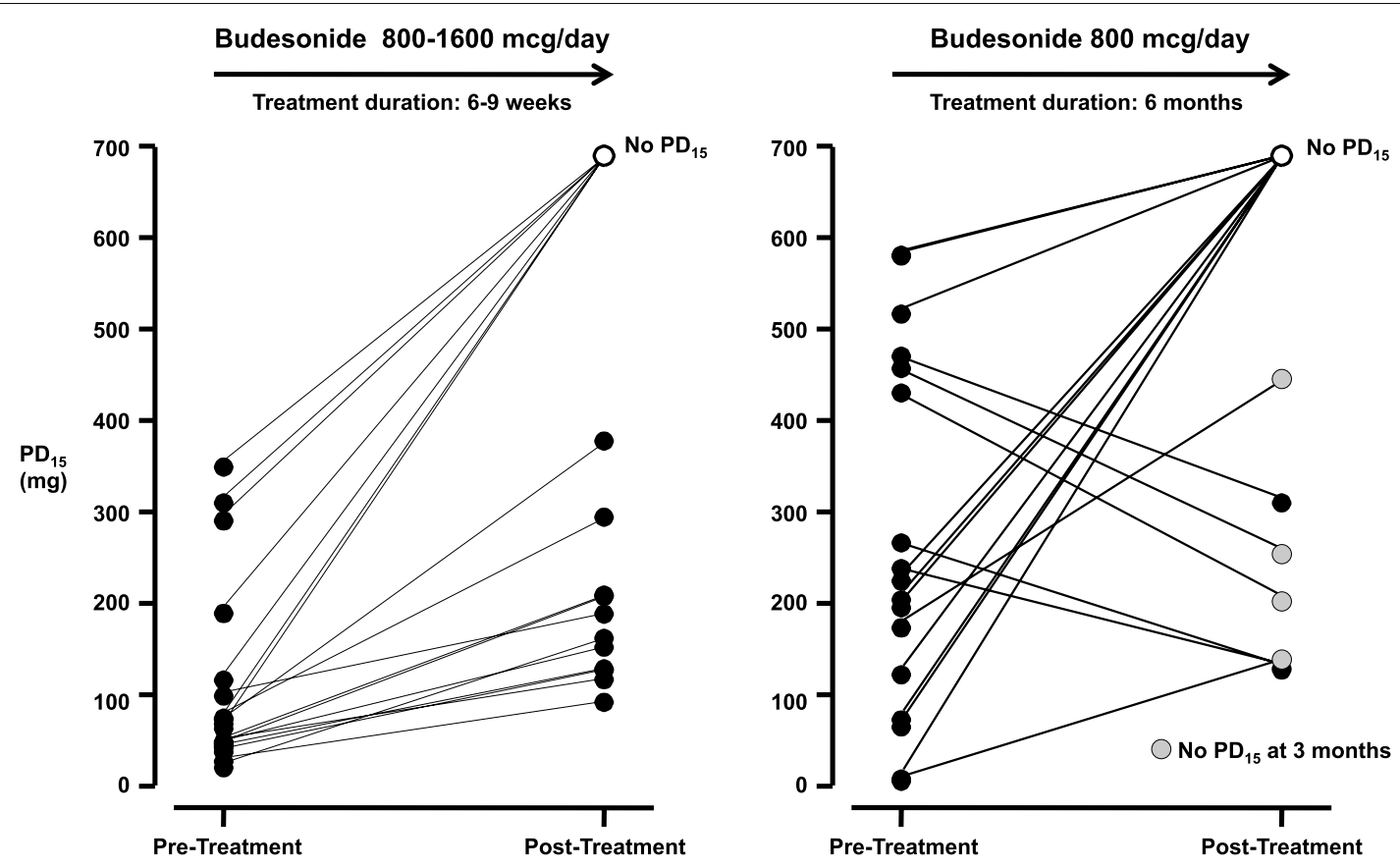

FIGURE 5 | The provoking dose of mannitol to cause a $15 \%$ fall in FEV $\left(\mathrm{PD}_{15}\right)$ following short-term (6-9 weeks) and long-term (6 months) treatment with inhaled corticosteroids (ICS; Brannan et al., 2002; Koskela et al., 2003). Following 6-9 weeks 7/18 subjects had no $\mathrm{PD}_{15}$. Following 6 months treatment $10 / 17$ subjects had no $\mathrm{PD}_{15}$ and

the airway reactivity was within the non-asthmatic range, however four subjects with a $\mathrm{PD}_{15}$ at 6 months had no $\mathrm{PD}_{15}$ at 3 months. AHR in individuals on ICS who were once negative to mannitol can result following a decrease in ICS dose (Leuppi et al., 2001) and suggest these subjects may have decreased ICS adherence. 
(Jonasson et al., 2000; Brannan et al., 2002; Koskela et al., 2003; Duong et al., 2008; Lipworth et al., 2012). There is also evidence of an increase in AHR to indirect stimuli in individuals with established asthma who have ICS withdrawn during down-titration of ICS (Leuppi et al., 2001). Improvements in airway sensitivity to mannitol with regular ICS occurs in association with the clinical improvements expected with ICS over weeks to months of treatment (Brannan et al., 2002; Koskela et al., 2003; Figure 5). Clinical questionnaires such the Asthma Control Questionnaire (Juniper et al., 1999b) and the Asthma Quality of Life Questionnaires (Juniper et al., 1999a) that have been validated to identify clinical improvement after weeks of ICS therapy (Juniper et al., 1994), show significant clinical improvements in AHR to mannitol following the introduction of ICS (Baraket et al., 2012; Turton et al., 2012). There are also improvements in airway reactivity with ICS which is documented as the response dose ratio (\% final fall in $\mathrm{FEV}_{1}$ divided by the dose of mannitol to cause that fall). This is a useful outcome to document efficacy of regular treatment using ICS that results in no significant reduction in $\mathrm{FEV}_{1}$ (i.e., $<10$ or $15 \%)$. The reactivity to mannitol can be reduced in asthmatics following effective ICS therapy to levels similar to those observed in non-asthmatic subjects (Brannan et al., 2012).

A recent study assessed the use of the mannitol challenge to monitor progress to ICS by re-assessing AHR every 2 months for a year following the introduction of ciclesonide. Those who had AHR monitored had significant reductions in mild exacerbations compared to those monitored using asthma guidelines (Lipworth et al., 2012). Those who had their asthma monitored using inhaled mannitol also had greater reductions in AHR to mannitol, methacholine, and FeNO levels compared to those monitored using guidelines. This finding suggested greater improvement in both AHR and airway inflammation with the AHR strategy. This was observed in association with significant improvements the frequency of night and day symptoms and decreased $\beta_{2}$-agonist use, which was not observed in those monitored using the reference strategy that used asthma guidelines. This study also showed more ICS were used in subjects managed using an AHR strategy, however this twofold increased dose of ciclesonide showed no

\section{REFERENCES}

Allen, N. D., Davis, B. E., and Cockcroft, D. W. (2008). Correlation between airway inflammation and loss of deep-inhalation bronchoprotection in asthma. Ann. Allergy Asthma Immunol. 101, 413-418.

Anderson, S. D. (2010). Indirect challenge tests: airway hyperresponsiveness in asthma: its measurement and clinical significance. Chest 138, 25S-30S.

Anderson, S. D., Brannan, J., Spring, J., Spalding, N., Rodwell, L. T., Chan, K., et al. (1997). A new method for bronchial-provocation testing in asthmatic subjects using a dry powder of mannitol. Am. J. Respir. Crit. Care Med. 156, 758-765.

Anderson, S. D., and Brannan, J. D. (2002). Exercise-induced asthma: is there still a case for histamine?

significant increase in urinary cortisol compared to the lower doses in the reference strategy. Considering this outcome, AHR to mannitol was mild but was still present over 12 months of ICS treatment.

When using an indirect stimulus to monitor ICS, an end point to identify optimal treatment is the documentation of no AHR to these stimuli (Koskela et al., 2003; Brannan et al., 2007). In both adults and children, it has been shown that a loss in responsiveness to these stimuli is possible following weeks to months of the commencement of ICS, with more rapid benefits (over 8-12 weeks) observed in those with milder AHR (Jonasson et al., 2000; Brannan et al., 2002). The loss of AHR to these stimuli suggests that there has been a significant decrease in the cellular source of mediators following regular ICS. The inhibition of indirect AHR in those initially demonstrating airway sensitivity to these stimuli before ICS, suggests a sufficient decrease in the presence and interaction of the key features of asthma, airway inflammation and AHR. Future studies need to address the longer-term clinical benefits on outcomes such as exacerbations and asthma control in those who achieve a loss of AHR to indirect stimuli following regular ICS therapy. Such a strategy may assist in achieving the required outcome of asthma guidelines that recommend control of asthma using the minimum dose of ICS [Global Initiative for Asthma (GINA), 2007].

\section{CONCLUSION}

Tests for AHR are useful objective measures to aid in asthma diagnosis by identifying a central feature of asthma. It is important to understand the differences in mechanisms between direct and indirect tests in order to employ them appropriately both in a clinical and research environment. Both direct and indirect tests for AHR have revealed much about the mechanisms of AHR in asthma, as well as the mechanisms of action of pharmacotherapy used to inhibit AHR. Future research should evaluate the features of airway remodeling that may contribute to the airway response as well as further evaluation of their role in monitoring asthma therapy such as ICS in order to achieve and sustain asthma control on minimal therapy.

of mannitol and methacholine to predict exercise-induced bronchoconstriction and a clinical diagnosis of asthma. Respir. Res. 10, 4.

Anderson, S. D., Rodwell, L. T., Daviskas, E., Spring, J. F., and Du Toit, J. (1996). The protective effect of nedocromil sodium and other drugs on airway narrowing provoked by hyperosmolar stimuli: a role for the airway epithelium? J. Allergy Clin. Immunol. 98, S124-S134; discussion S140-S122.

Andersson, C. K., Mori, M., Bjermer, L., Lofdahl, C. G., and Erjefalt, J. S. (2009). Novel site-specific mast cell subpopulations in the human lung. Thorax 64, 297-305.

Baraket, M., Oliver, B. G., Burgess, J. K., Lim, S., King, G. G., and Black, J. L. (2012). Is low dose inhaled corticosteroid therapy as effective for inflammation and remodeling in asthma? A randomized, parallel group study. Respir. Res. 13, 11.

Bel, E. H., Timmers, M. C., Hermans, J., Dijkman, J. H., and Sterk, P. J. (1990). The long-term effects of nedocromil sodium and beclomethasone dipropionate on bronchial responsiveness to methacholine in nonatopic asthmatic subjects. Am. Rev. Respir. Dis. 141, 21-28.

Boner, A. L., Vallone, G., Andreoli, A., Biancotto, R., and Warner, J. O. (1987). Nebulised sodium cromoglycate and verapamil in methacholine induced asthma. Arch. Dis. Child. 62, 264-268.

Boulet, L. P., Turcotte, H., and Tennina, S. (1989). Comparative efficacy of salbutamol, ipratropium, and cromoglycate in the prevention of bronchospasm induced by exercise 
and hyperosmolar challenges. J. Allergy Clin. Immunol. 83, 882-887.

Brannan, J. D. (2010). Bronchial hyperresponsiveness in the assessment of asthma control: airway hyperresponsiveness in asthma: its measurement and clinical significance. Chest 138, 11S-17S.

Brannan, J. D., Anderson, S. D., Freed, R., Leuppi, J. D., Koskela, H., and Chan, H. K. (2000). Nedocromil sodium inhibits responsiveness to inhaled mannitol in asthmatic subjects. Am. J. Respir. Crit. Care Med. 161, 2096-2099.

Brannan, J. D., Anderson, S. D., Gomes, K., King, G. G., Chan, H. K., and Seale, J. P. (2001). Fexofenadine decreases sensitivity to and montelukast improves recovery from inhaled mannitol. Am. J. Respir. Crit. Care Med. 163, 1420-1425.

Brannan, J. D., Anderson, S. D., Perry, C. P., Freed-Martens, R., Lassig, A. R., and Charlton, B. (2005). The safety and efficacy of inhaled dry powder mannitol as a bronchial provocation test for airway hyperresponsiveness: a phase 3 comparison study with hypertonic (4.5\%) saline. Respir. Res. $6,144$.

Brannan, J. D., Gulliksson, M., Anderson, S. D., Chew, N., and Kumlin, M. (2003). Evidence of mast cell activation and leukotriene release after mannitol inhalation. Eur. Respir. J. 22, 491-496.

Brannan, J. D., Gulliksson, M., Anderson, S. D., Chew, N., Seale, J. P., and Kumlin, M. (2006). Inhibition of mast cell PGD2 release protects against mannitol-induced airway narrowing. Eur. Respir. J. 27, 944-950.

Brannan, J. D., Koskela, H., and Anderson, S. D. (2007). Monitoring asthma therapy using indirect bronchial provocation tests. Clin. Respir. J. 1, 3-15.

Brannan, J. D., Koskela, H., Anderson, S. D., and Chan, H. K. (2002). Budesonide reduces sensitivity and reactivity to inhaled mannitol in asthmatic subjects. Respirology 7, 37-44.

Brannan, J. D., Koskela, H., Anderson, S. D., and Chew, N. (1998). Responsiveness to mannitol in asthmatic subjects with exercise- and hyperventilation-induced asthma. Am. J. Respir. Crit. Care Med. 158, 1120-1126.

Brannan, J. D., Perry, C. P., and Anderson, S. D. (2012). Mannitol test results in asthmatic adults receiving inhaled corticosteroids. J. Allergy Clin. Immunol. doi:10.1016/j.jaci.2012.08.028
Brightling, C. E., Bradding, P., Symon, F. A., Holgate, S. T., Wardlaw, A. J., and Pavord, I. D. (2002). Mast-cell infiltration of airway smooth muscle in asthma. N. Engl. J. Med. 346, 1699-1705

Britton, J., Pavord, I., Richards, K., Knox, A., Wisniewski, A., Wahedna, I., et al. (1994). Factors influencing the occurrence of airway hyperreactivity in the general population: the importance of atopy and airway calibre. Eur. Respir. J. 7, 881-887.

Cheung, D., Timmers, M. C., Zwinderman, A. H., Bel, E. H., Dijkman, J. H., and Sterk, P. J. (1992). Longterm effects of a long-acting beta 2-adrenoceptor agonist, salmeterol, on airway hyperresponsiveness in patients with mild asthma. N. Engl. J. Med. 327, 1198-1203.

Cockcroft, D. W. (2010). Direct challenge tests: airway hyperresponsiveness in asthma: its measurement and clinical significance. Chest 138 , 18S-24S.

Cockcroft, D. W., and Nair, P. (2012). Methacholine test and the diagnosis of asthma. J. Allergy Clin. Immunol. 130, 556.

Cowan, D. C., Hewitt, R. S., Cowan, J. O., Palmay, R., Williamson, A., Lucas, S. J., et al. (2010). Exerciseinduced wheeze: fraction of exhaled nitric oxide-directed management. Respirology 15, 683-690.

Crapo, R. O., Casaburi, R., Coates, A. L., Enright, P. L., Hankinson, J. L., Irvin, C. G., et al. (2000). Guidelines for methacholine and exercise challenge testing-1999. This official statement of the American Thoracic Society was adopted by the ATS Board of Directors, July 1999. Am. J. Respir. Crit. Care Med. 161, 309-329.

Crimi, E., Brusasco, V., Brancatisano, M., Losurdo, E., and Crimi, P. (1987). Effect of nedocromil sodium on adenosine- and methacholineinduced bronchospasm in asthma. Clin. Allergy 17, 135-141.

Crimi, E., Spanevello, A., Neri, M., Ind, P. W., Rossi, G. A., and Brusasco, V. (1998). Dissociation between airway inflammation and airway hyperresponsiveness in allergic asthma. Am. J. Respir. Crit. Care Med. 157, 4-9.

Crimi, N., Palermo, F., Oliveri, R., Polosa, R., Settinieri, I., and Mistretta, A. (1992). Protective effects of inhaled ipratropium bromide on bronchoconstriction induced by adenosine and methacholine in asthma. Eur. Respir. J. 5, 560-565.

Dahlen, B., Roquet, A., Inman, M. D., Karlsson, O., Naya, I., Anstren, G., et al. (2002). Influence of zafirlukast and loratadine on exercise-induced bronchoconstriction. J. Allergy Clin. Immunol. 109, 789-793.

Davis, B. E., and Cockcroft, D. W. (2005). Effect of a single dose of montelukast sodium on methacholine chloride PC20. Can. Respir. J. 12, 26-28.

Djukanovic, R., Wilson, J. W., Britten, K. M., Wilson, S. J., Walls, A. F., Roche, W. R., et al. (1992). Effect of an inhaled corticosteroid on airway inflammation and symptoms in asthma. Am. Rev. Respir. Dis. 145 669-674.

Dougherty, R. H., Sidhu, S. S., Raman, K., Solon, M., Solberg, O. D., Caughey, G. H., et al. (2010). Accumulation of intraepithelial mast cells with a unique protease phenotype in $\mathrm{T}(\mathrm{H})$ 2-high asthma. J. Allergy Clin. Immunol. 125, 1046-1053.e1048.

du Toit, J. I., Anderson, S. D., Jenkins, C. R., Woolcock, A. J., and Rodwell, L. T. (1997). Airway responsiveness in asthma: bronchial challenge with histamine and $4.5 \%$ sodium chloride before and after budesonide. Allergy Asthma Proc. 18, 7-14.

Duong, M., Subbarao, P., Adelroth, E., Obminski, G., Strinich, T., Inman, M., et al. (2008). Sputum eosinophils and the response of exercise-induced bronchoconstriction to corticosteroid in asthma. Chest 133, 404-411.

Eggleston, P. A., Kagey-Sobotka, A., Proud, D., Adkinson, N. F. Jr., and Lichtenstein, L. M. (1990). Disassociation of the release of histamine and arachidonic acid metabolites from osmotically activated basophils and human lung mast cells. Am. Rev. Respir. Dis. 141, 960-964.

Eggleston, P. A., Kagey-Sobotka, A. Schleimer, R. P., and Lichtenstein, L. M. (1984). Interaction between hyperosmolar and IgE-mediated histamine release from basophils and mast cells. Am. Rev. Respir. Dis. 130, 86-91.

Foresi, A., Mastropasqua, B., Chetta, A., D’Ippolito, R., Testi, R., Olivieri, D. et al. (2005). Step-down compared to fixed-dose treatment with inhaled fluticasone propionate in asthma. Chest 127, 117-124.

Gibson, P. G., Saltos, N., and Borgas, T. (2000). Airway mast cells and eosinophils correlate with clinical severity and airway hyperresponsiveness in corticosteroid-treated asthma. J. Allergy Clin. Immunol. 105, 752-759.

Gibson, P. G., Wlodarczyk, J. W., Hensley, M. J., Gleeson, M., Henry, R. L., Cripps, A. W., et al. (1998). Epidemiological association of airway inflammation with asthma symptoms and airway hyperresponsiveness in childhood. Am. J. Respir. Crit. Care Med. 158, 36-41.

Global Initiative for Asthma (GINA). (2007). "Global strategy for asthma and management and prevention," in NHLBI/WHO Workshop Report, ed. N. H. National Institutes of Health, Lung and Blood Institute (Bethesda, MA: Medical Communication Resources, Inc.), 16-19.

Groot, C. A., Lammers, J. W., Molema, J., Festen, J., and Van Herwaarden, C. L. (1992). Effect of inhaled beclomethasone and nedocromil sodium on bronchial hyperresponsiveness to histamine and distilled water. Eur. Respir. J. 5, 1075-1082.

Gulliksson, M., Palmberg, L., Nilsson, G., Ahlstedt, S., and Kumlin, M. (2006). Release of prostaglandin D2 and leukotriene $\mathrm{C} 4$ in response to hyperosmolar stimulation of mast cells. Allergy 61, 1473-1479.

Haby, M. M., Anderson, S. D., Peat, J. K., Mellis, C. M., Toelle, B. G., and Woolcock, A. J. (1994). An exercise challenge protocol for epidemiological studies of asthma in children: comparison with histamine challenge. Eur. Respir. J. 7, 43-49.

Hakim, F., Vilozni, D., Adler, A., Livnat, G., Tal, A., and Bentur, L. (2007). The effect of montelukast on bronchial hyperreactivity in preschool children. Chest 131, 180-186.

Hallstrand, T. S., Lai, Y., Johnson, B., Frevert, C. W., Hudkins, K. L., Hyde, D. M., et al. (2011). Intraepithelial mast cells with a unique phenotype in the airways of asthmatic patients with exercise-induced bronchoconstriction. Am. J. Respir. Crit. Care Med. 183, A4418.

Hallstrand, T. S., Moody, M. W., Wurfel, M. M., Schwartz, L. B., Henderson, W. R. Jr., and Aitken, M. L. (2005). Inflammatory basis of exercise-induced bronchoconstriction. Am. J. Respir. Crit. Care Med. 172, 679-686.

Hancox, R. J., Subbarao, P., Kamada, D., Watson, R. M., Hargreave, F. E., and Inman, M. D. (2002). Beta2-agonist tolerance and exercise-induced bronchospasm. Am. J. Respir. Crit. Care Med. 165, 1068-1070.

Haney, S., and Hancox, R. J. (2005). Rapid onset of tolerance to betaagonist bronchodilation. Respir. Med. 99, 566-571.

Haney, S., and Hancox, R. J. (2006). Recovery from bronchoconstriction and bronchodilator tolerance. Clin. Rev. Allergy Immunol. 31, 181-196. 
Hewitt, D. J. (2008). Interpretation of the "positive" methacholine challenge. Am. J. Ind. Med. 51, 769-781.

Holgate, S. T., Arshad, H. S., Roberts, G. C., Howarth, P. H., Thurner, P., and Davies, D. E. (2010). A new look at the pathogenesis of asthma. Clin. Sci. $118,439-450$.

Holley, A. B., Cohee, B., Walter, R. J., Shah, A. A., King, C. S., and Roop, S. (2012). Eucapnic voluntary hyperventilation is superior to methacholine challenge testing for detecting airway hyperreactivity in nonathletes. J. Asthma 49, 614-619.

Holzer, K., Anderson, S. D., Chan, H. K., and Douglass, J. (2003). Mannitol as a challenge test to identify exerciseinduced bronchoconstriction in elite athletes. Am. J. Respir. Crit. Care Med. 167, 534-537.

Holzer, K., Anderson, S. D., and Douglass, J. (2002). Exercise in elite summer athletes: challenges for diagnosis. J. Allergy Clin. Immunol. 110, 374-380.

Illamperuma, C., Davis, B. E., Fenton, M. E., and Cockcroft, D. W. (2009). Duration of bronchoprotection of inhaled ipratropium against inhaled methacholine. Ann. Allergy Asthma Immunol. 102, 438-439.

Irwin, R. S. (2006). Assessing cough severity and efficacy of therapy in clinical research: ACCP evidencebased clinical practice guidelines. Chest 129, 232S-237S.

Jatakanon, A., Lim, S., Kharitonov, S. A., Chung, K. F., and Barnes, P. J. (1998). Correlation between exhaled nitric oxide, sputum eosinophils, and methacholine responsiveness in patients with mild asthma. Thorax 53, 91-95.

Jenkins, C. R., Thien, F. C., Wheatley, J. R., and Reddel, H. K. (2005). Traditional and patient-centred outcomes with three classes of asthma medication. Eur. Respir. J. 26, 36-44.

Jonasson, G., Carlsen, K. H., and Hultquist, C. (2000). Low-dose budesonide improves exerciseinduced bronchospasm in schoolchildren. Pediatr. Allergy Immunol. 11, 120-125.

Joos, G. F., O'Connor, B., Anderson, S. D., Chung, F., Cockcroft, D. W., Dahlen, B., et al. (2003). Indirect airway challenges. Eur. Respir. J. 21, 1050-1068.

Juniper, E. F., Buist, A. S., Cox, F. M., Ferrie, P. J., and King, D. R. (1999a). Validation of a standardized version of the Asthma Quality of Life Questionnaire. Chest 115, 1265-1270.

Juniper, E. F., O’Byrne, P. M., Guyatt, G. H., Ferrie, P. J., and King, D. R. (1999b). Development and validation of a questionnaire to measure asthma control. Eur. Respir. J. 14, 902-907.

Juniper, E. F., Guyatt, G. H., Willan, A., and Griffith, L. E. (1994). Determining a minimal important change in a disease-specific Quality of Life Questionnaire. J. Clin. Epidemiol.47, 81-87.

Juniper, E. F., Kline, P. A., Vanzieleghem, M. A., Ramsdale, E. H., O'Byrne, P. M., and Hargreave, F. E. (1990). Effect of long-term treatment with an inhaled corticosteroid (budesonide) on airway hyperresponsiveness and clinical asthma in nonsteroid-dependent asthmatics. Am. Rev. Respir. Dis. 142, 832-836.

Kalra, S., Swystun, V. A., Bhagat, R., and Cockcroft, D. W. (1996). Inhaled corticosteroids do not prevent the development of tolerance to the bronchoprotective effect of salmeterol. Chest 109, 953-956.

Kapsali, T., Permutt, S., Laube, B., Scichilone, N., and Togias, A. (2000). Potent bronchoprotective effect of deep inspiration and its absence in asthma. J. Appl. Physiol. 89, 711-720.

Kelly, K. D., Spooner, C. H., and Rowe, B. H. (2001). Nedocromil sodium versus sodium cromoglycate in treatment of exercise-induced bronchoconstriction: a systematic review. Eur. Respir. J. 17, 39-45.

Kippelen, P., Fitch, K. D., Anderson, S. D., Bougault, V., Boulet, L. P., Rundell, K. W., et al. (2012). Respiratory health of elite athletes - preventing airway injury: a critical review. $\mathrm{Br}$. J. Sports Med. 46, 471-476.

Kippelen, P., Larsson, J., Anderson, S. D., Brannan, J. D., Dahlen, B., and Dahlen, S. E. (2010). Effect of sodium cromoglycate on mast cell mediators during hyperpnea in athletes. Med. Sci. Sports Exerc. 42, 1853-1860.

Kivity, S., Argaman, A., Onn, A., Shwartz, Y., Man, A., Greif, J., et al. (2000). Eosinophil influx into the airways in patients with exerciseinduced asthma. Respir. Med. 94, 1200-1205.

Knopfli, B. H., Bar-Or, O., and Araujo, C. G. (2005). Effect of ipratropium bromide on EIB in children depends on vagal activity. Med. Sci. Sports Exerc. 37, 354-359.

Koh, M. S., Tee, A., Lasserson, T. J., and Irving, L. B. (2007). Inhaled corticosteroids compared to placebo for prevention of exercise induced bronchoconstriction. Cochrane Database Syst. Rev. CD002739.

Koh, Y. I., and Choi, S. (2002). Blood eosinophil counts for the prediction of the severity of exercise-induced bronchospasm in asthma. Respir. Med. 96, 120-125.

Koskela, H. O., Hyvarinen, L., Brannan, J. D., Chan, H. K., and Anderson, S. D. (2003). Sensitivity and validity of three bronchial provocation tests to demonstrate the effect of inhaled corticosteroids in asthma. Chest 124 1341-1349.

Koskela, H. O., Hyvarinen, L., Brannan, J. D., Chan, H. K., and Anderson, S. D. (2004). Coughing during mannitol challenge is associated with asthma. Chest 125, 1985-1992.

Koskela, H. O., Martens, R., Brannan, J. D., Anderson, S. D. Leuppi, J., and Chan, H. K. (2005). Dissociation in the effect of nedocromil on mannitol-induced cough or bronchoconstriction in asthmatic subjects. Respirology 10 442-448.

Leuppi, J. D., Salome, C. M., Jenkins, C. R., Anderson, S. D., Xuan, W., Marks, G. B., et al. (2001). Predictive markers of asthma exacerbation during stepwise dose reduction of inhaled corticosteroids. Am. J. Respir. Crit. Care Med. 163, 406-412.

Liem, J. J., Kozyrskyj, A. L., Cockroft, D. W., and Becker, A. B. (2008). Diagnosing asthma in children: what is the role for methacholine bronchoprovocation testing? Pediatr. Pulmonol. 43, 481-489.

Lim, S., Jatakanon, A., John, M., Gilbey, T., O'Connor B, J., Chung, K. F., et al. (1999). Effect of inhaled budesonide on lung function and airway inflammation. Assessment by various inflammatory markers in mild asthma. Am. J. Respir. Crit. Care Med. 159, 22-30.

Lipworth, B. J., Short, P. M., Williamson, P. A., Clearie, K. L., Fardon, T. C., and Jackson, C. M. (2012). A randomized primary care trial of steroid titration against mannitol in persistent asthma: STAMINA trial. Chest 141, 607-615.

Litonjua, A. A., Sparrow, D., and Weiss, S. T. (1999). The FEF25-75/FVC ratio is associated with methacholine airway responsiveness. The normative aging study. Am. J. Respir. Crit. Care Med. 159, 1574-1579.

Lougheed, D. M., Webb, K. A., and O'Donnell, D. E. (1995). Breathlessness during induced lung hyperinflation in asthma: the role of the inspiratory threshold load. Am. J. Respir. Crit. Care Med. 152, 911-920.

Lougheed, M. D., Lam, M., Forkert, L. Webb, K. A., and O'Ddonnell, D. E. (1993). Breathlessness during acute bronchoconstriction in asthma.
Pathophysiologic mechanisms. Am. Rev. Respir. Dis. 148, 1452-1459.

Mai, X. M., Bottcher, M. F., Bruhammar, M., Nilsson, L., and Zetterstrom, O. (2005). Urinary inflammatory mediators and inhalation of hypertonic saline in children. Allergy 60 , 60-64.

McFadden, E. R. Jr., and Zawadski, D. K. (1996). Vocal cord dysfunction masquerading as exercise-induced asthma. A physiologic cause for "choking" during athletic activities. Am. J. Respir. Crit. Care Med. 153, 942-947.

McGrath, K. W., and Fahy, J. V. (2011). Negative methacholine challenge tests in subjects who report physician-diagnosed asthma. Clin. Exp. Allergy 41, 46-51.

Mickleborough, T. D., Murray, R. L., Ionescu, A. A., and Lindley, M. R. (2003). Fish oil supplementation reduces severity of exercise-induced bronchoconstriction in elite athletes. Am. J. Respir. Crit. Care Med. 168, 1181-1189.

Nuijsink, M., Hop, W. C., Sterk, P. J., Duiverman, E. J., and De Jongste, J. C. (2007). Long-term asthma treatment guided by airway hyperresponsiveness in children: a randomised controlled trial. Eur. Respir. J. 30 457-466.

O’Byrne, P. M., Gauvreau, G. M., and Brannan, J. D. (2009a). Provoked models of asthma: what have we learnt? Clin. Exp. Allergy 39, 181-192.

O’Byrne, P. M., Van Der Linde, J., Cockcroft, D. W., Gauvreau, G. M., Brannan, J. D., Fitzgerald, M., et al. (2009b). Prolonged bronchoprotection against inhaled methacholine by inhaled BI 1744, a longacting beta(2)-agonist, in patients with mild asthma. J. Allergy Clin. Immunol. 124, 1217-1221.

O'Connor, B. J., Towse, L. J., and Barnes, P. J. (1996). Prolonged effect of tiotropium bromide on methacholine-induced bronchoconstriction in asthma. Am. J. Respir. Crit. Care Med. 154, 876-880.

O’Hickey, S. P., Arm, J. P., Rees, P. J., Spur, B. W., and Lee, T. H. (1988). The relative responsiveness to inhaled leukotriene $\mathrm{E} 4$, methacholine and histamine in normal and asthmatic subjects. Eur. Respir. J. 1, 913-917.

O'Sullivan, S., Roquet, A., Dahlen, B., Dahlen, S., and Kumlin, M. (1998a) Urinary excretion of inflammatory mediators during allergen-induced early and late phase asthmatic reactions. Clin. Exp. Allergy 28, 1332-1339. 
O'Sullivan, S., Roquet, A., Dahlen, B., Larsen, F., Eklund, A., Kumlin, M., et al. (1998b). Evidence for mast cell activation during exercise-induced bronchoconstriction. Eur. Respir. J. 12, 345-350.

Page, C. P., and Spina, D. (2006). Beta2agonists and bronchial hyperresponsiveness. Clin. Rev. Allergy Immunol. 31, 143-162.

Parameswaran, K. N., Inman, M. D., Ekholm, B. P., Morris, M. M., Summers, E., O’Byrne, P. M., et al. (1999). Protection against methacholine bronchoconstriction to assess relative potency of inhaled beta2-agonist. Am. J. Respir. Crit. Care Med. 160, 354-357.

Parker, A. L., Abu-Hijleh, M., and McCool, F. D. (2003). Ratio between forced expiratory flow between 25\% and $75 \%$ of vital capacity and FVC is a determinant of airway reactivity and sensitivity to methacholine. Chest 124, 63-69.

Parker, A. L., and McCool, F. D. (2002). Pulmonary function characteristics in patients with different patterns of methacholine airway hyperresponsiveness. Chest 121, 1818-1823.

Patel, K. R. (1984). Sodium cromoglycate in histamine and methacholine reactivity in asthma. Clin. Allergy 14, 143-145.

Porsbjerg, C., and Brannan, J. D. (2010). Alternatives to exercise challenge for the objective assessment of exercise-induced bronchospasm: eucapnic voluntary hyperpnoea and the osmotic challenge tests. Breathe 7, 53-63.

Porsbjerg, C., Brannan, J. D., Anderson, S. D., and Backer, V. (2008). Relationship between airway responsiveness to mannitol and to methacholine and markers of airway inflammation, peak flow variability and quality of life in asthma patients. Clin. Exp. Allergy 38, 43-50.

Porsbjerg, C., Lund, T. K., Pedersen, L., and Backer, V. (2009). Inflammatory subtypes in asthma are related to airway hyperresponsiveness to mannitol and exhaled NO. J. Asthma 46, 606-612.

Pyrgos, G., Scichilone, N., Togias, A., and Brown, R. H. (2011). Bronchodilation response to deep inspirations in asthma is dependent on airway distensibility and air trapping. J. Appl. Physiol. 110, 472-479.

Ramsdale, E. H., Morris, M. M., Roberts, R. S., and Hargreave, F. E. (1985).
Asymptomatic bronchial hyperresponsiveness in rhinitis. J. Allergy Clin. Immunol. 75, 573-577.

Reddel, H. K., Jenkins, C. R., Marks, G. B., Ware, S. I., Xuan, W., Salome, C. M., et al. (2000). Optimal asthma control, starting with high doses of inhaled budesonide. Eur. Respir. J. 16, 226-235.

Reiss, T. F., Hill, J. B., Harman, E., Zhang, J., Tanaka, W. K., Bronsky, E., et al. (1997). Increased urinary excretion of LTE4 after exercise and attenuation of exercise-induced bronchospasm by montelukast, a cysteinyl leukotriene receptor antagonist. Thorax 52, 1030-1035.

Rundell, K. W., and Spiering, B. A. (2003). Inspiratory stridor in elite athletes. Chest 123, 468-474.

Ryan, G., Dolovich, M. B., Roberts, R. S., Frith, P. A., Juniper, E. F., Hargreave, F. E., et al. (1981). Standardization of inhalation provocation tests: two techniques of aerosol generation and inhalation compared. Am. Rev. Respir. Dis. 123, 195-199.

Scichilone, N., Marchese, R., Soresi, S., Interrante, A., Togias, A., and Bellia, V. (2007). Deep inspiration-induced changes in lung volume decrease with severity of asthma. Respir. Med. 101, 951-956.

Scollo, M., Zanconato, S., Ongaro, R., Zaramella, C., Zacchello, F., and Baraldi, E. (2000). Exhaled nitric oxide and exercise-induced bronchoconstriction in asthmatic children. Am. J. Respir. Crit. Care Med. 161, 1047-1050.

Sears, M. R., Greene, J. M., Willan, A. R., Wiecek, E. M., Taylor, D. R., Flannery, E. M., et al. (2003). A longitudinal, population-based, cohort study of childhood asthma followed to adulthood. N. Engl. J. Med. 349, 1414-1422.

Simpson, J. L., Scott, R., Boyle, M. J., and Gibson, P. G. (2006). Inflammatory subtypes in asthma: assessment and identification using induced sputum. Respirology 11, 54-61.

Sont, J. K., Han, J., Van Krieken, J. M., Evertse, C. E., Hooijer, R., Willems, L. N., et al. (1996). Relationship between the inflammatory infiltrate in bronchial biopsy specimens and clinical severity of asthma in patients treated with inhaled steroids. Thorax 51, 496-502.

Sont, J. K., Willems, L. N., Bel, E. H., Van Krieken, J. H., Vandenbroucke,
J. P., and Sterk, P. J. (1999). Clinical control and histopathologic outcome of asthma when using airway hyperresponsiveness as an additional guide to long-term treatment. The AMPUL Study Group. Am. J. Respir. Crit. Care Med. 159, 1043-1051.

Sue-Chu, M., Brannan, J. D., Anderson, S. D., Chew, N., and Bjermer, L. (2010). Airway hyperresponsiveness to methacholine, adenosine 5monophosphate, mannitol, eucapnic voluntary hyperpnoea and field exercise challenge in elite crosscountry skiers. Br. J. Sports Med. 44, 827-832.

Sumino, K., Sugar, E. A., Irvin, C. G., Kaminsky, D. A., Shade, D., Wei, C. Y., et al. (2012). Methacholine challenge test: diagnostic characteristics in asthmatic patients receiving controller medications. J. Allergy Clin. Immunol. 130, 69-75.e66.

Sunyer, J., Anto, J. M., Kogevinas, M., Soriano, J. B., Tobias, A., and Munoz, A. (1997). Smoking and bronchial responsiveness in nonatopic and atopic young adults. Spanish Group of the European Study of Asthma. Thorax 52, 235-238.

Tarlo, S. M., Balmes, J., Balkissoon, R. Beach, J., Beckett, W., Bernstein, D. et al. (2008). Diagnosis and management of work-related asthma: American College of Chest Physicians Consensus Statement. Chest 134, 1S-41S.

Tashkin, D. P., Altose, M. D., Bleecker, E. R., Connett, J. E., Kanner, R. E., Lee, W. W., et al. (1992). The lung health study: airway responsiveness to inhaled methacholine in smokers with mild to moderate airflow limitation. The Lung Health Study Research Group. Am. Rev. Respir. Dis. 145, 301-310.

Todd, D. C., Davis, B. E., Hurst, T. S., and Cockcroft, D. W. (2004). Dosimeter methacholine challenge: comparison of maximal versus submaximal inhalations. J. Allergy Clin. Immunol. 114, 517-519.

Turcotte, S. E., and Lougheed, M. D. (2011). Cough in asthma. Curr. Opin. Pharmacol. 11, 231-237.

Turton, J. A., Glasgow, N. J., and Brannan, J. D. (2012). Feasibility and acceptability of using bronchial hyperresponsiveness to manage asthma in primary care: a pilot study. Prim. Care Respir. J. 21, 28-34.
Van Den Berge, M., Meijer, R. J., Kerstjens, H. A., De Reus, D. M., Koeter, G. H., Kauffman, H. F., et al. (2001). PC(20) adenosine 5 '-monophosphate is more closely associated with airway inflammation in asthma than PC(20) methacholine. Am. J. Respir. Crit. Care Med. 163, 1546-1550.

Van Schoor, J., Joos, G. F., and Pauwels, R. A. (2000). Indirect bronchial hyperresponsiveness in asthma: mechanisms, pharmacology and implications for clinical research. Eur. Respir. J. 16, 514-533.

Weinberger, M., and Abu-Hasan, M. (2007). Pseudo-asthma: when cough, wheezing, and dyspnea are not asthma. Pediatrics 120, 855-864.

Woolcock, A. J., and Peat, J. K. (1989). Epidemiology of bronchial hyperresponsiveness. Clin. Rev. Allergy 7, 245-256.

Yoshikawa, T., Shoji, S., Fujii, T., Kanazawa, H., Kudoh, S., Hirata, K. et al. (1998). Severity of exerciseinduced bronchoconstriction is related to airway eosinophilic inflammation in patients with asthma. Eur. Respir. J. 12, 879-884.

Conflict of Interest Statement: Dr. John D. Brannan was involved in the development of inhaled mannitol (Ari$\mathrm{dol}^{\mathrm{TM}} /$ Osmohale $\left.{ }^{\mathrm{TM}}\right)$ that is a registered bronchial provocation test for airway hyperresponsiveness to assist in the diagnosis of asthma. He receives a $10 \%$ portion of the Royalties paid to his prior employer, Royal Prince Alfred Hospital. He holds shares in Pharmaxis Ltd.

Received: 29 August 2012; paper pending published: 24 September 2012; accepted: 19 November 2012; published online: 10 December 2012.

Citation: Brannan JD and Lougheed MD (2012) Airway hyperresponsiveness in asthma: mechanisms, clinical significance, and treatment. Front. Physio. 3:460. doi: 10.3389/fphys.2012.00460

This article was submitted to Frontiers in Respiratory Physiology, a specialty of Frontiers in Physiology.

Copyright (C) 2012 Brannan and Lougheed. This is an open-access article distributed under the terms of the Creative Commons Attribution License, which permits use, distribution and reproduction in other forums, provided the original authors and source are credited and subject to any copyright notices concerning any third-party graphics etc. 